\title{
Propionate Induces Virulent Properties of Crohn's Disease-Associated Escherichia coli
}

\author{
Olga V. Pobeguts ${ }^{1 *}$, Valentina G. Ladygina ${ }^{1}$, Daria V. Evsyutina ${ }^{1}$, Artem V. Eremeev', \\ Aleksandr I. Zubov' ${ }^{1}$, Daria S. Matyushkina ${ }^{1}$, Peter L. Scherbakov' ${ }^{2}$, Daria V. Rakitina ${ }^{1}$ and \\ Gleb Y. Fisunov ${ }^{1}$
}

1 Department of Molecular Biology and Genetics, Federal Research and Clinical Centre of Physical and Chemical Medicine, Federal Medical-Biological Agency, Moscow, Russia, ${ }^{2}$ A. S. Loginov Moscow Clinical Scientific Center, Moscow, Russia

\section{OPEN ACCESS}

Edited by:

Marie-Joelle Virolle,

Centre National de la Recherche Scientifique (CNRS), France

Reviewed by:

Carla Camprubi-Font, University of Girona, Spain Wolfgang Buckel,

University of Marburg, Germany

*Correspondence: Olga V. Pobeguts nikitishena@mail.ru

Specialty section:

This article was submitted to Microbial Physiology and Metabolism,

a section of the journal

Frontiers in Microbiology

Received: 28 November 2019

Accepted: 04 June 2020

Published: 08 July 2020

Citation:

Pobeguts OV, Ladygina VG, Evsyutina DV, Eremeev AV, Zubov Al, Matyushkina DS, Scherbakov PL, Rakitina DV and Fisunov GY (2020)

Propionate Induces Virulent Properties of Crohn's

Disease-Associated Escherichia coli.

Front. Microbiol. 11:1460.

doi: 10.3389/fmicb.2020.01460
Crohn's disease (CD) is a severe chronic immune-mediated granulomatous inflammatory disease of the gastrointestinal tract. The mechanisms of CD pathogenesis remain obscure. Metagenomic analysis of samples from CD patients revealed that several of them have the elevated level of Escherichia coli with adhesive-invasive phenotype (AIEC). Previously, we isolated an E. coli strain CD isolate ZVL2 from a patient with $\mathrm{CD}$, which features AIEC phenotype. Here, we demonstrate that prolonged growth on propionate containing medium stimulates virulent properties of $C D$ isolate $Z V L 2$, while prolonged growth on glucose reduces these properties to levels indistinguishable from laboratory strain K-12 MG1655. Propionate presence also boosts the ability of $\mathrm{CD}$ isolate $\mathrm{ZVL} 2$ to penetrate and colonize macrophages. The effect of propionate is reversible, re-passaging of CD isolate on M9 medium supplemented with glucose leads to the loss of its virulent properties. Proteome analysis of CD isolate ZVL2 growth in medium supplemented with propionate or glucose revealed that propionate induces expression porins OmpA and OmpW, transcription factors PhoP and OmpR, and universal stress protein UspE, which were previously found to be important for macrophage colonization by enteropathogenic bacteria.

\footnotetext{
Keywords: Crohn's disease, Crohn's disease-associated adherent-invasive Escherichia coli, propionic acid, 2D electrophoresis, macrophages
}

\section{INTRODUCTION}

Crohn's disease $(\mathrm{CD})$ is a severe chronic immune-mediated granulomatous inflammatory disease of the gastrointestinal tract. It can affect each and every region of the gastrointestinal tract from the oral cavity to the rectum. Key signs of the CD include diarrhea, intestinal bleeding, abdominal pain, anemia, and weight loss (Ng et al., 2018). The CD pathogenesis is a multifactorial process, which includes genetic factors, gut microbiota composition, and immune-mediated damage of the intestine (Torres et al., 2017). The mechanisms and the causes of the CD are being extensively studied in recent years but remain obscure to a large extent. The metagenomic analysis of patients' gut microbiota demonstrated the characteristic increase of representation of Escherichia coli strains (Gevers et al., 2014), several of which are able to penetrate the mucin layer, adhere to the epithelial cells, cross the epithelial barrier, and colonize macrophages (Rhodes, 2007). These E. coli can modulate macrophages' defensive functions to avoid lysis (Bringer et al., 2006). These 
strains were collectively assigned to the adhesive-invasive group of E. coli (AIEC). It has been demonstrated that AIEC do not feature any known genetic determinants that are characteristic to enteroinvasive, enteropathogenic, and enterotoxigenic E. coli or Shigella flexneri (like invasin or intimin of enteropathogenic E. coli) (Boudeau et al., 2000). It was shown that the AIEC infection is associated with the release of pro-inflammatory cytokines (Lapaquette et al., 2012). It indicates that colonization of macrophages leads to an increase of inflammation, which in turn increases the amount of new macrophages, which are used for further colonization. AIEC were introduced as a pathotype along with the role of agent provocateur they were supposed to play in the CD pathogenesis (Strober, 2011). Their pathogenic potential was supported by phylogenetic relationship observed between genomes of some AIEC and extracellular pathogenic E. coli, which causes urinary tract infections and neonatal meningitis (Miquel et al., 2010; Nash et al., 2010). In addition, Schippa et al. found a significantly higher representation of virulent genes in AIEC from CD patients. These studies have also confirmed the "pathobiont" nature of AIEC strains (Schippa et al., 2012; Conte et al., 2014). In addition, AIEC differ from the opportunistic pathogens because their pathogenic effect is mediated by the stimulation of the host's immune system (Hornef, 2015). The determinants that are responsible for transition to the adhesive-invasive phenotype and the macrophage colonization are still unknown. In order to outcompete the species of normal gut microbiota, pathogens use different mechanisms including inflammation induction, direct or indirect eradication of commensal species, and use of alternative nutrients (Stecher, 2015). There is a growing amount of data that indicate that the majority of enteropathogens feature specific metabolic pathways, which allow them to use alternative carbon sources (Staib and Fuchs, 2014). It has been demonstrated that they are able to utilize ethanolamine, which is formed during catabolism of phospholipids, fucose or rhamnose, propionate, and several other metabolites that are unavailable for the commensal bacteria (Ferreyra et al., 2014; Staib and Fuchs, 2014; Ormsby et al., 2018, 2019). Due to that fact that the study of metabolic pathways that aid macrophage colonization is an urgent task for researchers, earlier we sequenced $28 \mathrm{E}$. coli isolates from 10 patients with CD (Rakitina et al., 2017). In this work, we aimed to study the effect of different carbon sources including glucose and propionate on the adhesive-invasive phenotype and the ability to survive in macrophages of a selected $E$. coli isolate, $\mathrm{CD}$ isolate $\mathrm{ZvL} 2$, which is one of the isolates obtained by our group in 2017 (isolate RCE07, Rakitina et al., 2017). Propionic acid is a common gut metabolite. It is known that short-chain fatty acids are naturally formed as the metabolites of the normal gut microbiota in anaerobic conditions. Up to $90 \%$ of the fatty acid species within the gut represent acetic, butyric, and propionic acids (Cummings et al., 1987). Of these three species, propionate and acetate can be utilized by E. coli. It metabolizes propionate via the 2-methylcitrate cycle (Figure 1) (Ormsby et al., 2019). This pathway is initiated via the activation of propionate to propionyl-CoA by three pathways. The first pathway is common for Enterobacteriales and is catalyzed by propionyl-CoA synthetase (PrpE) (Ormsby et al., 2019). This

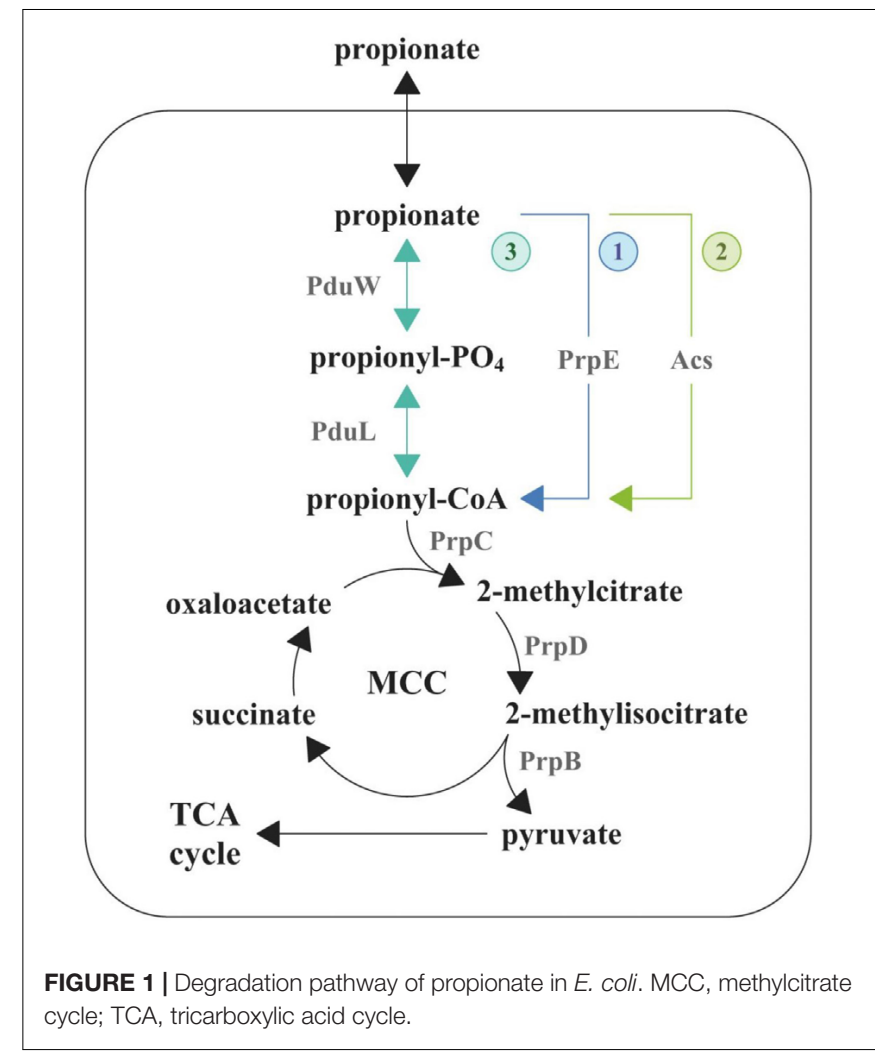

gene is located in the prpBCDE operon with other members of 2-methylcitrate cycle and is regulated by the PrpR transcriptional regulator. These genes form the $\operatorname{prp} R \operatorname{prpBCDE}$ divergon (Suvorova et al., 2012). The second pathway is catalyzed by acetyl-CoA synthetase (Acs), which is under post-translational control by acetylation by CobB (Liu et al., 2014). The third way is a two-step conversion of propionate to propionylphosphate by propionate kinase (PduW) and then phosphate propionyl transferase PduL converts propionyl-phosphate to propionyl-CoA. The third pathway has been identified in Salmonella enterica serovar Typhimurium (Palacios et al., 2003; Liu et al., 2007). The subsequent condensation of oxaloacetate with propionyl-CoA is catalyzed by the 2-methylcitrate synthase (PrpC) resulting in the production of 2-methylcitrate. In the next step, the 2-methylcitrate dehydratase (PrpD) isomerizes 2methylcitrate to 2-methylisocitrate, which is further cleaved to pyruvate and succinate by the 2-methylisocitrate lyase (PrpB).

It was shown previously that the propionate can stimulate adhesive-invasive properties and acid stress resistance of AIEC (Ormsby et al., 2018, 2019), unlike antimicrobial effect on Salmonella typhimurium (Hung et al., 2013). In addition, Ormsby et al. (2019) identified that the propionate serves as a metabolic signal, which stimulates utilization of ethanolamine. It is still unknown how propionate induces the adhesive-invasive properties of E. coli and its ability to survive in macrophages. In order to identify the major changes that occur upon change of carbon source, we carried out comparative proteome analysis of $\mathrm{CD}$ isolate of $E$. coli grown on glucose and propionate using $2 \mathrm{D}$ electrophoresis. 


\section{MATERIALS AND METHODS}

\section{Cell Cultures}

Escherichia coli isolate ZvL2 (CD isolate ZvL2) was obtained by an endoscopic surgery of a patient with $\mathrm{CD}$ at The Loginov Moscow Clinical Scientific Center. Sample collection was carried out in accordance with the requirements of the local Ethics Committee based on the informed consent of the patient. $\mathrm{CD}$ isolate $\mathrm{ZvL} 2$ was sequenced by our group (isolate RCE07, Rakitina et al., 2017) and identified that it belongs to phylogroup A. Laboratory strain K-12 MG1655 and CD isolate ZvL2 were cultivated on M9 medium with a supplement of $50 \mathrm{mM}$ glucose (Glu) or $20 \mathrm{mM}$ sodium propionate $(\mathrm{PA})$ at $37^{\circ} \mathrm{C}$ and $180 \mathrm{r} / \mathrm{min}$. Growth curve was monitored using $\mathrm{OD}$ at $600 \mathrm{~nm}$. R package Growthcurver was used to fit growth curve data to the logistic equation (Sprouffske and Wagner, 2016). The value of arguments ( $\mathrm{r}$ the growth rate, $\mathrm{n} 0$-the initial population size, t_gen-the maximum doubling time, etc.) was extracted (Supplementary Figure S2 and Supplementary Table S3).

Caco- 2 cell line was cultivated in DMEM with the addition of $10 \%$ of bovine fetal serum at $37^{\circ} \mathrm{C}$ and $5 \% \mathrm{CO}_{2}$. THP- 1 cell line was cultivated in RPMI 1640 medium with the addition of $10 \%$ of bovine fetal serum at $37^{\circ} \mathrm{C}$ and $5 \% \mathrm{CO}_{2}$. Macrophages were differentiated using the standard 72-h protocol using $200 \mathrm{nM} 13$ phorbol-12-myristate acetate (Starr et al., 2018).

\section{RNA Purification and cDNA Synthesis}

RNA isolation was performed as described above (Gorbachev et al., 2013). One-hundred-microliter aliquots of E. coli culture were directly lyzed in TRIzol LS reagent (Life Technologies) at a 1:3 ratio of culture medium:TRIzol LS (v/v). The nucleic acids were extracted with chloroform and precipitated by the addition of an equal volume of isopropanol and subsequent centrifugation. The pallets were washed with $80 \%$ ethanol and finally resuspended in $20 \mu \mathrm{l}$ of $\mathrm{mQ}$ (Panreac). The amount of RNA was determined using the Qubit 2.0 fluorometer (Thermo Fisher Scientific). The resulting RNA was treated by DNAse I (Thermo Scientific), and cDNA was synthesized from random hexamer primers by Maxima $\mathrm{H}$ Minus Reverse Transcriptase (Thermo Scientific) according to the manufacturer's protocol.

\section{qRT-PCR}

Quantitative real-time PCR was performed using dNTP, PCR buffer, Taq-polymerase (Lytech), SYBR Green I (Invitrogen), and CFX96 $6^{\text {TM }}$ Real-Time PCR Detection System (Bio-Rad) PCR machine. Primers used are listed in Supplementary Table S1. All primers were designed using BAC-Browser (Garanina et al., 2018). Each $20-\mu 1$ reaction contained $0.2 \mu \mathrm{l}$ of template cDNA. Thermal cycling conditions were as follows: initial denaturation at $95^{\circ} \mathrm{C}$ for $1 \mathrm{~min}$, then 40 -cycle amplification $\left(94^{\circ} \mathrm{C}\right.$ for $15 \mathrm{~s}$, $58^{\circ} \mathrm{C}$ for $20 \mathrm{~s}$, and $68^{\circ} \mathrm{C}$ for $1 \mathrm{~min}$ ) with a single fluorescence per reading. Melting curve was obtained by gradually heating the PCR mixture from 65 to $94^{\circ} \mathrm{C}$ at a rate of $0.5^{\circ} \mathrm{C}$ every $5 \mathrm{~s}$, with continuous fluorescence scanning. Relative expression for each sample was determined using the $2^{-\Delta \Delta \mathrm{Ct}}$ method with normalization to the amount of gyrA transcripts present in the RNA samples. qRT-PCR experiments were carried out on three biological replicates per strain, for each condition. Significance of changes was calculated using $t$-test in $\mathrm{R}$.

The efficiency of the PCR amplification was determined for all primer pairs. Standard curves were plotted for five twofold serial dilutions of cDNA. The slope of the standard curve was used to calculate the PCR efficiency. For all primers, PCR efficiency was $96-104 \%$. Two technical repeats were used (Supplementary Table S2 and Supplementary Figure S1).

\section{DNA Extraction}

Escherichia coli cells were harvested by centrifugation $(5000 \mathrm{~g}$ for $5 \mathrm{~min}, 4^{\circ} \mathrm{C}$ ) and lyzed with CTAB buffer [2\% CTAB, $100 \mathrm{mM}$ Tris- $\mathrm{HCl}$ ( $\mathrm{pH} \mathrm{8.0),} 20 \mathrm{mM}$ EDTA, and $1.4 \mathrm{M} \mathrm{NaCl}]$ at $60^{\circ} \mathrm{C}$ for $30 \mathrm{~min}$ with subsequent chloroform extraction (1:1) and isopropanol precipitation (1:1) with the addition of $10 \% \mathrm{v} / \mathrm{v} 3 \mathrm{M}$ sodium acetate ( $\mathrm{pH}$ 5.2) (Stewart and Via, 1993). The amount of DNA was determined using the Qubit 2.0 fluorometer (Thermo Fisher Scientific). The genomic DNA of laboratory strain K12 MG1655 and CD isolate ZvL2 was used as matrix for PCR amplification of acs, cobB, prpE genes, and intergenic regions of $\operatorname{prpR}, \operatorname{prpB}$, and $p r p C$. PCR was performed using dNTP, PCR buffer, Taq-polymerase (Lytech), and Tetrad 2 Peltier Thermal Cycler (Bio-Rad). Primers used are listed in Supplementary Table S1. Thermal cycling conditions were the same as that described in qRT-PCR section with a few differences: only 22 cycles of PCR were used and the duration of elongation step depended on the final amplicon length, assuming that processivity of Taq-polymerase (Lytech) is 1000 bp/s. Agarose gel electrophoresis was performed to verify the size and purity of the PCR products [1.5\% w/v agarose, $90 \mathrm{mM}$ Tris-borate $(\mathrm{pH}$ 8.3 ), and $0.5 \mu \mathrm{g} / \mathrm{ml}$ ethidium bromide]. The sequences of the amplicons were obtained by Sanger dideoxy sequencing method using Bigdye Terminator v.3.1 Cycle Sequencing Kit and ABI Prism Genetic Analyzer 3730XL following the manufacturer's instructions (Applied Biosystem).

\section{Analysis of Adhesive and Invasive Properties of $E$. coli}

Analysis of adhesive-invasive potential was carried out on Caco2 cells as described earlier (Olivares-Morales et al., 2018), with some modifications. The layer of Caco-2 cells was infected by CD isolate ZvL2 at 1:10 ratio. Prior to infection, E. coli cells were diluted by sterile PBS buffer to $0.1 \mathrm{OD}_{600}$ centrifuged at $5000 \mathrm{~g}$ for $5 \mathrm{~min}$, washed again in PBS, and then centrifuged and resuspended in $1 \mathrm{ml}$ of DMEM. The infected cells were incubated for $3 \mathrm{~h}$ at $37^{\circ} \mathrm{C}$ and $5 \% \mathrm{CO}_{2}$. After incubation, a subset of the wells was washed two times by PBS to remove non-attached bacteria. Then $0.5 \mathrm{ml}$ of $0.5 \%$ Triton X-100 in PBS was added to the wells and incubated for $5 \mathrm{~min}$. The lysate was collected into $0.5 \mathrm{ml}$ of LB broth. These samples contained cells that were attached to or engulfed in Caco-2 cells. The rest of the wells were incubated for $2 \mathrm{~h}$ more. After that, the medium was removed and fresh aliquots of $1 \mathrm{ml}$ of DMEM supplied with gentamicin $(300 \mu \mathrm{g} / \mathrm{ml})$ were added and 
the cells were incubated for $1 \mathrm{~h}$ at $37^{\circ} \mathrm{C}$ and $5 \% \mathrm{CO}_{2}$. After that, the wells were washed with PBS and the Caco-2 cells were lyzed by Triton X-100 as described above. The obtained samples of E. coli in Caco-2 lysates were plated on solid LB agar and cultivated overnight at $37^{\circ} \mathrm{C}$. Then, the numbers of CFUs were calculated (Supplementary Figure S3) and the values of percent adhesion-invasion and invasion compared to the initial inoculum were determined. The analysis has been carried out in three biological replicates.

\section{Analysis of Survival in Macrophages}

The survival rate of laboratory strain K-12 MG1655 and CD isolate ZvL2 was assayed as described earlier (Migliore et al., 2018) with some modifications. Macrophages of the THP-1 cell line were infected by $E$. coli in a 1:100 ratio. E. coli cells were washed from the medium as described above and resuspended in RPMI 1640 medium. One milliliter of the suspension was added per well. The plates were centrifuged at $1000 \mathrm{~g}$ for $10 \mathrm{~min}$ and incubated for $1 \mathrm{~h}$ at $37^{\circ} \mathrm{C}$ and $5 \% \mathrm{CO}_{2}$ to allow internalization. Cell monolayers were washed twice in PBS to remove extracellular bacteria and treated with RPMI containing gentamicin $(300 \mu \mathrm{g} / \mathrm{ml} ; 20$-fold the MIC for both CD isolate ZvL2 and MG1655) for $1 \mathrm{~h}$ to kill non-internalized bacteria. Subsequently, monolayers of part of wells were washed twice with sterile PBS and lyzed by the addition of deionized water with $0.5 \%$ (vol/vol) Triton X-100 for $5 \mathrm{~min}$, to release internalized bacteria. In order to obtain the bacterial titer precisely, cell lysates were serially diluted, $50 \mu \mathrm{l}$ of each dilution was plated on solid LB agar and incubated at $37^{\circ} \mathrm{C}$ overnight, and CFU (and thus the number of internalized bacteria) were determined ( $1 \mathrm{~h}$ postinfection). The remaining unlyzed monolayers were incubated for 6 and $24 \mathrm{~h}$. After incubation, the monolayers were washed twice with sterile PBS and lyzed in deionized water containing $0.5 \%$ (vol/vol) Triton X-100 for $5 \mathrm{~min}$ to release the bacteria that have survived the incubation. Dilution series of the lysates were plated on solid LB agar and incubated at $37^{\circ} \mathrm{C}$ overnight. Then, the numbers of CFUs were calculated (Supplementary Figure S4) and the number of bacterial populations that survived during 6 and $24 \mathrm{~h}$ incubation in macrophages was estimated (6 h and $24 \mathrm{~h}$ postinfection). The analysis has been carried out in six biological replicates.

\section{D-DIGE of CHAPS-Soluble Fraction of E. coli, Tryptic Digestion, and Protein Identification}

Differential 2D gel-electrophoresis, tryptic digestion of the proteins, and protein identification by MALDI-ToF mass spectrometry were performed as described above (Fisunov et al., 2011). The gels were scanned on a Typhoon Trio (Amersham) scanner at $532 \mathrm{~nm}$ (Cy3) and $633 \mathrm{~nm}$ (Cy5) $500 \mathrm{pmt}$ laser intensity. Quantitative analysis was performed using PDQuest 8.0 software (Bio-Rad). For spot excision, the gels were stained by silver as described by Shevchenko et al. (1996). The spots of interest were excised and washed in mixing solution containing $15 \mathrm{mM}$ tetrathionate and $50 \mathrm{mM}$ potassium ferrocyanide. Then, the gel pieces were washed in $\mathrm{mQ}$ water until the yellow color disappeared. Then, gel pieces were dried in 100\% acetonitrile. Three to four microliters of trypsin solution ( $40 \mathrm{mM}$ ammonium bicarbonate, $10 \%$ acetonitrile, and $40 \mathrm{nM}$ trypsin) was added to each sample and the samples were incubated for $30 \mathrm{~min}$ on ice and subsequently for $16-17 \mathrm{~h}$ at $37^{\circ} \mathrm{C}$. Peptide extraction was performed by addition of $0.5 \% \mathrm{v} / \mathrm{v}$ TFA in $\mathrm{mQ}$ water. The samples were incubated in an ultrasonic bath for $10 \mathrm{~min}$ and then incubated for $1 \mathrm{~h}$ at room temperature. Mass spectrometric analysis was performed on Ultraflex II MALDI-ToF-ToF (Bruker Daltonics) as described earlier (Zgoda et al., 2006). Proteins were identified against the protein database of CD isolate ZvL2 (Rakitina et al., 2017). The identification cutoff was $44(p<0.05)$.

\section{Statistical Analysis}

Descriptive statistics of mean values, standard deviation (SD), and confidence intervals (CI) were performed using Origin 8.2 software (OriginLab, Northampton, MA, United States). Spearman rank correlation was calculated using R-3.6.3.

\section{RESULTS}

\section{Comparison of Genes and Pathways Related to Propionate Degradation in CD Isolate ZvL2 and E. coli K12-MG1655}

We compared sequences of genes involved in metabolism of propionate in isolates ZvL2 and E. coli K12 MG1655. Some genes (acs, $c o b B$, and prpE) have frameshifts in the genome of ZvL2 probably due to the sequencing error. We amplified these genes from genomic DNA with specific primers and sequenced using the Sanger method. There were no frameshifts found in these genes. The comparison of the intergenic regions of $\operatorname{prpR}$ and $\operatorname{prpBCDE}$ of ZvL2 and K-12 MG1655 revealed several differences: first, substitution in -10-box of $p r p R$, the activator of prpBCDE (Figure 2), and second, there are different amounts of repeats between $p r p B$ and $p r p C$. These genes are transcribed as polycistronic mRNA under aerobic conditions. However, under anaerobic conditions, the transcription of each gene is regulated separately. It has been proposed that the regulation takes place on a post-transcriptional level. The key role in this process is played by RNase R, which may target the repeats between these genes (Simonte et al., 2017). The difference in the number of repeats between $p r p B$ and $p r p C$ was confirmed by PCR and Sanger sequencing (Figure 3). The comparison of the coding sequences of $p r p B C D E$ did not reveal any differences. The coding sequence of $\operatorname{prpR}$ features few amino acid substitutions (SAPs), but they do not seem to impact its function. Search for $p d u W$ and $p d u L$ homologs in K-12 MG1655 and ZvL2 revealed that both encode protein $\mathrm{TdcD}$ that share $44 \%$ sequence identity with PduW of Salmonella and $99 \%$ between each other. Substitutions in $t d c D$ of K-12 MG1655 and ZvL2 are not located in critical positions. pduL homolog was found only in ZvL2 with $80 \%$ of sequence identity. Alternatively, the function of $p d u L$ may be taken by $p t a$ (phosphate acetyltransferase), which is common for both strains (Palacios et al., 2003). Thus, the main differences between ZvL2 and K-12 MG1655 are mutation in the -10 box of $p r p R$, different 


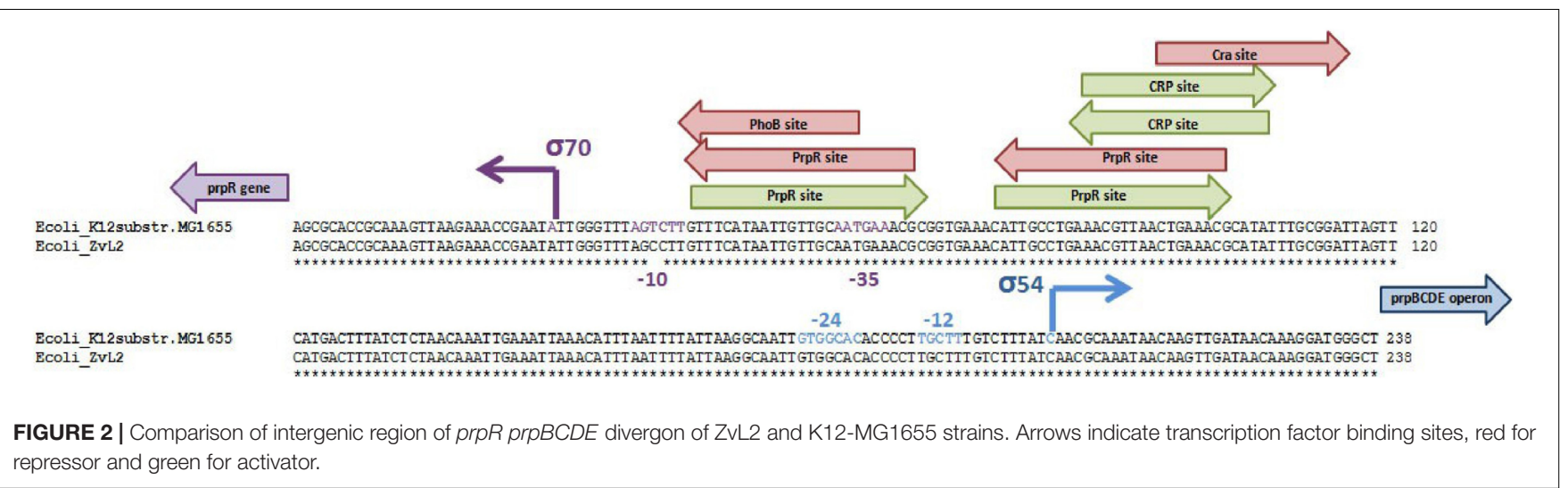

amount of repeats between $\operatorname{prp} B$ and $\operatorname{prp} C$, and absence of $p d u L$ in the laboratory strain.

\section{Isolate ZvL2 Shows Faster Adaptation to M9 Minimal Medium Supplied With Propionate}

Crohn's disease isolate ZvL2 and K-12 MG1655 laboratory strain were cultivated on M9 minimal medium with the addition of either $50 \mathrm{mM}$ of glucose (Glu) or $20 \mathrm{mM}$ of sodium propionate (PA). The amount of supplied propionate was chosen taking into account the data on concentration of propionic acid in the human gut. It was demonstrated that its concentration varies

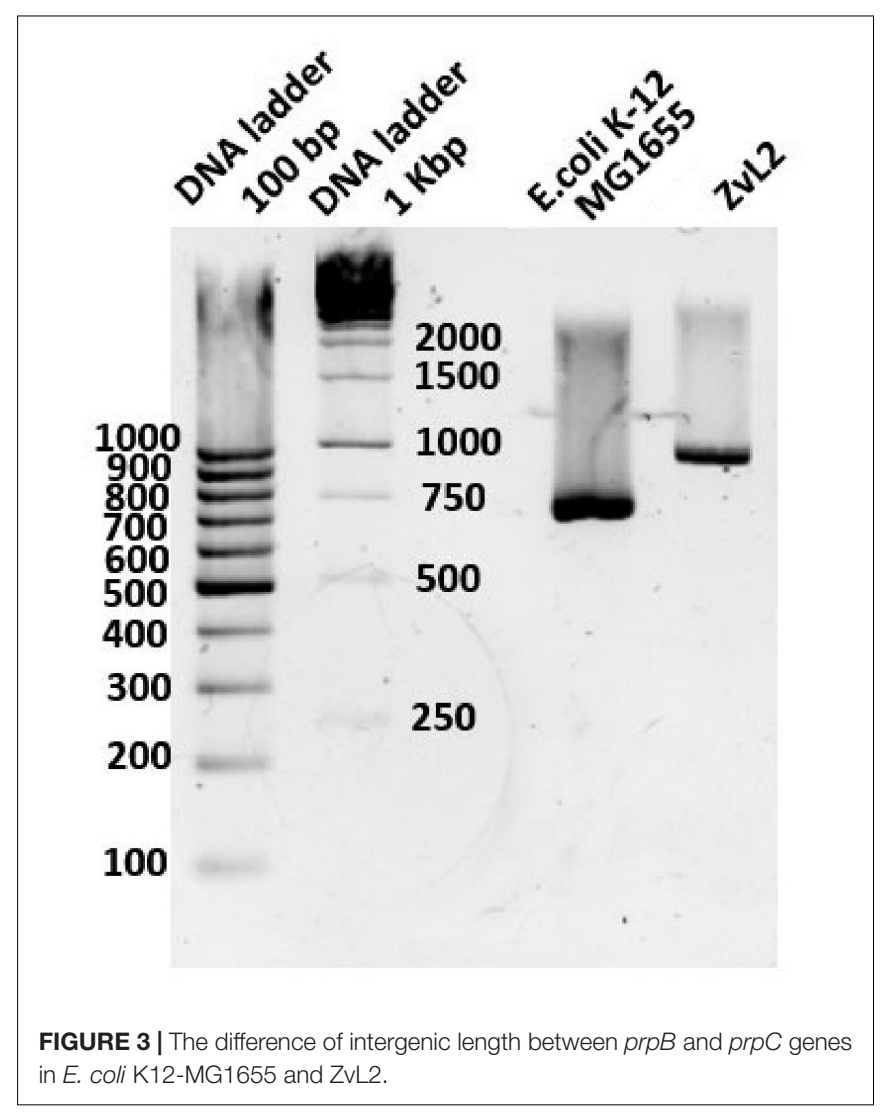

across the different parts of the gastrointestinal tract and reaches a maximum of $27 \mathrm{mM}$ in the colon (Ormsby et al., 2018). Figure 4 demonstrates growth curves of CD isolate ZvL2 and K-12 MG1655 laboratory strain on M9 minimal medium in the presence of glucose and propionate. The growth rates of both strains on glucose medium are similar. However, growth curves on propionate show drastic differences. CD isolate ZvL2 grows significantly faster than K-12 MG1655. The growth rate of CD isolate $\mathrm{ZvL} 2$ on propionate at the first $6 \mathrm{~h}$ does not differ from the growth rate on glucose, while K-12 MG1655 on propionate showed almost no signs of growth at all. The growth rate of K12 MG1655 on propionate can be evaluated only about $12 \mathrm{~h}$ later than CD isolate $\mathrm{ZvL} 2$.

To further assess the growth parameters of the strains, we modeled the experimental data using the non-linear regression with Verhulst equation. The model predicted doubling time and maximum population capacity (Crow and Kimura, 1970; Rockwood, 2015; Sprouffske and Wagner, 2016). The population

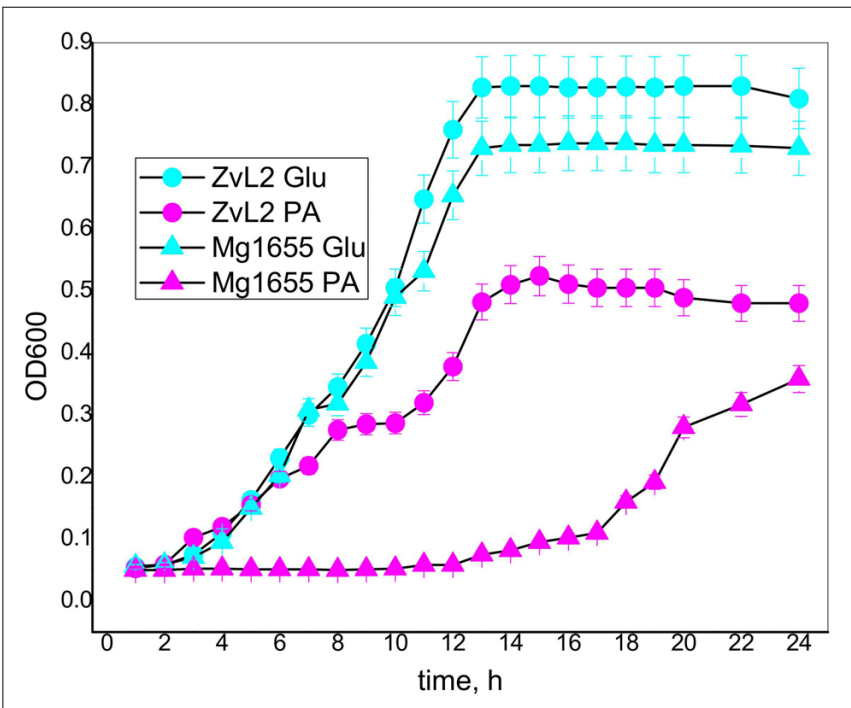

FIGURE 4 | The growth curves of the CD isolate ZVL2 and laboratory strain K 12Mg1655 in minimal media M9 supplemented with glucose (ZvL2Glu) (50 mM) or sodium propionate (ZvL2PA) $(20 \mathrm{mM})$ as a carbon source. 
capacity was comparable for each of the strains on the same energy source and was higher on glucose than on PA. The doubling time was not significantly different for both strains under both conditions (Supplementary Figure S2 and Supplementary Table S3). The doubling time of K-12 MG1655 was about $1.3 \mathrm{~h}$ at both conditions. For ZvL2, it was about $1.3 \mathrm{~h}$ on glucose, but $1.8 \mathrm{~h}$ on PA. This indicates that the retarded growth of K-12 MG1655 is due to the longer lag phase. One can speculate that K-12 MG1655 cells die on PA, and the released nutrients are used by survivors for further growth. However, only $5 \%(\mathrm{v} / \mathrm{v})$ of cell culture is transferred in the fresh medium for the experiment. Thus, the amount of spare biomass provided by dead cells is negligible compared to final biomass, so it cannot reach the observed values without the use of PA from the medium. We propose that K-12 MG1655 strain needs time to adapt to growth on PA, while ZvL2 is prepared for it. Later, the growth rate of CD isolate $\mathrm{ZvL} 2$ on propionate decreases, probably due to inhibition of fructose-1,6-bisphosphatase by increasing concentration of 2-methylisocitrate (Rocco and Escalante-Semerena, 2010).

\section{Propionate Induces Expression of Operon Only in ZvL2 Isolate}

We measured transcription of genes involved in propionate utilization in K-12 MG1655 and ZvL2 strains in M9 medium supplied with glucose and propionate using RTqPCR (Figure 5). Transcription of prpBCDE operon was significantly induced only by propionate in $\mathrm{ZvL} 2$ strain compared to K-12 MG1655. In particular, induction of $p r p B$ was higher than that of the downstream genes of the operon. In addition, propionate induced transcription of acetylCoA synthase (acs) in ZvL2 strain. The ability to upregulate expression of propionate utilization enzymes may explain the observed difference in adaptation of $\mathrm{ZvL} 2$ and $\mathrm{K}-12$ MG1655 to propionate.

\section{Propionic Acid Exacerbates and Glucose Reduces the Adhesive and Invasive Phenotype of AIEC}

We used colon carcinoma cell line Caco-2 to study the adhesive and invasive properties of $\mathrm{CD}$ isolate ZvL2 grown on M9 medium supplied with glucose or propionate. We prepared $\mathrm{CD}$ isolate $\mathrm{ZvL} 2$ by three methods of cultivation: cells grown on M9 medium with glucose for one passage from colony (ZvL2), cells grown on M9 medium with glucose for five passages $(\mathrm{ZvL} 2 \mathrm{Glu})$, and cells grown on M9 medium with propionate for five passages (ZvL2PA). The control laboratory strain was treated in the same fashion. Figure 6 demonstrates that cultures ZvL2 and ZvL2PA feature adhesive-invasive phenotype.

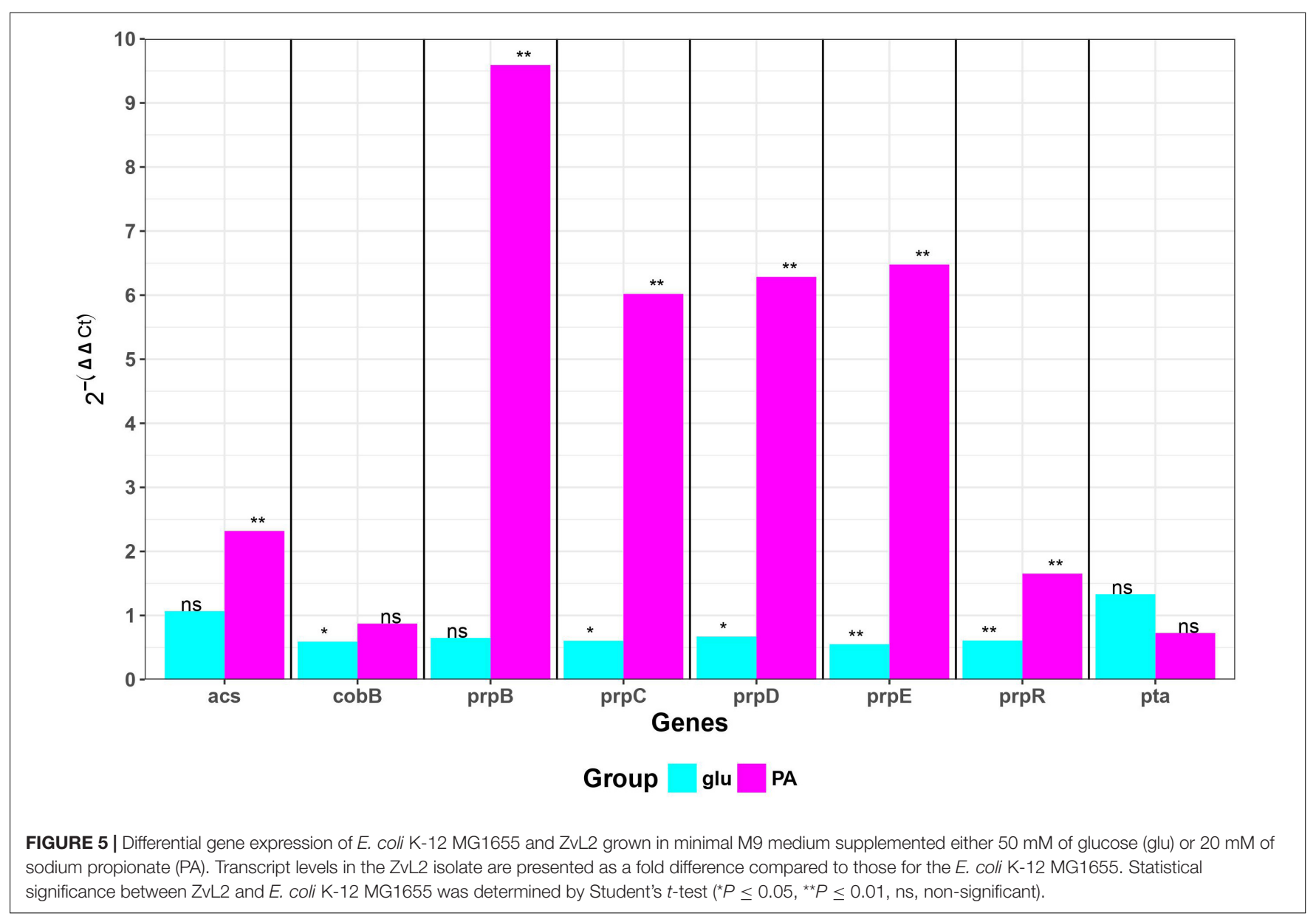




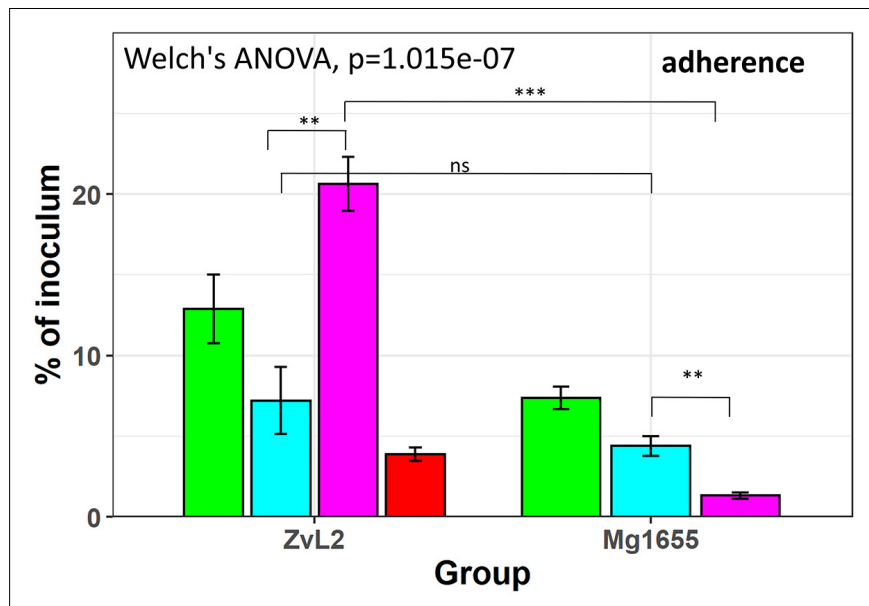

Condition $\square$ initial $\square$ Glu $\square$ PA $\square$ PA-Glu

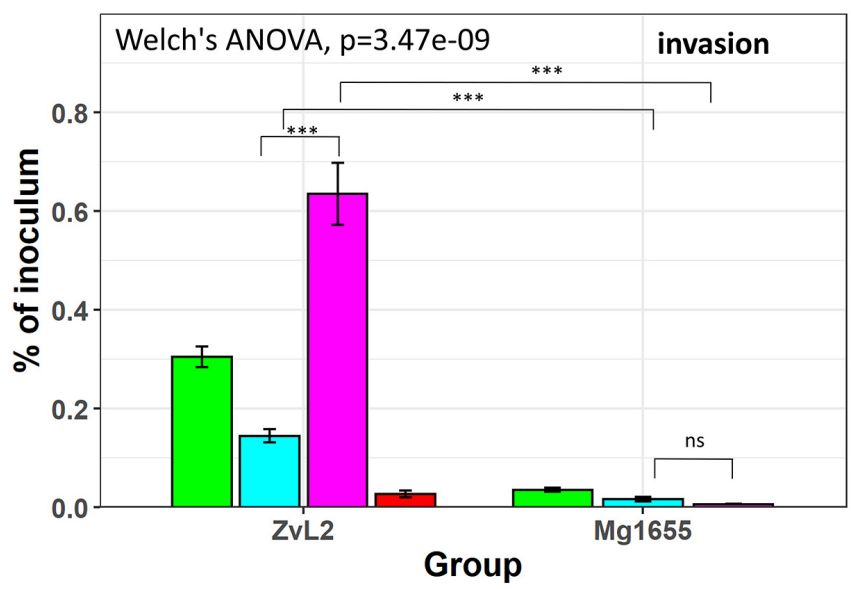

Condition $\square$ initial $\square$ Glu $\square$ PA $\square$ PA-Glu

FIGURE 6 | Adhesion and invasion of CDprotect isolate ZvL2 and K-12 MG1655 laboratory strain to intestinal epithelial cells Caco-2. ZvL2, Mg1655-after one passage and ZvL2 Glu, Mg1655 Glu - after five passages from colony on minimal M9 medium supplemented with glucose, ZvL2 PA, Mg1655 PA_after five passages from colony in minimal M9 medium supplemented with sodium propionate. ZVL2 PA-Glu-re-passaging on M9 medium supplemented with glucose after sodium propionate. The kinetics of adhesion and invasion were measured up to 3 and $5 \mathrm{~h}$ at an $\mathrm{MOI}$ of 10 . Adhesion and invasion were also represented as a percentage of initial inoculums. Data are expressed as the means \pm SD from three independent experiments. ${ }^{\star} P \leq 0.05$, ${ }^{\star \star} P \leq 0.01$, ${ }^{\star \star \star} P \leq 0.001$.

The rate of adhesion-invasion is $15 \%$ and $20 \%$ and the rate of invasion is 0.3 and $0.64 \%$ for $\mathrm{ZvL} 2$ and $\mathrm{ZvL} 2 \mathrm{PA}$, respectively, though passaging on glucose $(\mathrm{ZvL} 2 \mathrm{Glu})$ reduces adhesion-invasion rate to $7 \%$ and invasion rate to $0.14 \%$. Passaging on both glucose and propionate of K-12 MG1655 did not increase adhesive and invasive properties. Thus, longterm growth on glucose drastically reduces the adhesive and invasive properties of $\mathrm{CD}$ isolate $\mathrm{ZvL} 2$, while propionate induces adhesive-invasive phenotype. However, we did not observe the effect of propionate on K-12 MG1655.

\section{Propionate Increases and Glucose Decreases the Survival Rate of CD Isolate ZvL2 in Macrophages}

Since macrophage infection is an important component of $\mathrm{CD}$ pathogenesis, we tested the ability of $\mathrm{CD}$ isolate $\mathrm{ZvL} 2$ to colonize macrophages. The efficiency of phagocytosis of $\mathrm{CD}$ isolate ZvL2 and K-12 MG1655 strain by human macrophages and the survival rate of the strains were measured by gentamicin test using THP-1 macrophage cell line. Macrophages were cultivated for $1 \mathrm{~h}$ with the E. coli strains. Then, the macrophages were treated with gentamicin to remove $E$. coli that were not internalized by macrophages. The part of wells was washed twice with sterile PBS and lyzed by the addition of deionized water with $0.5 \%$ ( $\mathrm{vol} / \mathrm{vol}$ ) Triton $\mathrm{X}-100$ for $5 \mathrm{~min}$, to release internalized bacteria. In Figure 7 , at $1 \mathrm{~h} \mathrm{PI}$ is the number of internalized bacteria during $1 \mathrm{~h}$ of postinfection. The average number of internalized bacteria was three E. coli per macrophage. The survival rate was assayed as percent of the remaining CFU after 6 and $24 \mathrm{~h}$ of cultivation. We demonstrate that $\mathrm{CD}$ isolate $\mathrm{ZvL} 2$ is more resistant to macrophages' lysosomes compared to K-12 MG1655 strain. The survival rate of CD isolate ZvL2 is 41 and $28 \%$ after 6 and $24 \mathrm{~h}$, respectively. In comparison, the survival rate of K-12 MG1655 is 20.5 and $11.7 \%$. The ability of CD isolate $\mathrm{ZvL} 2$ to survive in macrophages decreases to the values of laboratory strain after the passaging on glucose. In particular, 6 and 24 -h survival rates decreased to 24 and $10.6 \%$, respectively. In contrast, passaging on propionate increases survival rate to 49 and $35 \%$, respectively. We did not observe the effect of propionate for K12 MG1655 (after five passages on this carbon source) after 6 and $24 \mathrm{~h}$ of postinfection. The effect of propionate is reversible, re-passaging of CD isolate on M9 medium supplemented with glucose after five passages on propionate leads to the drastic decrease of the survival rate.

Thus, we obtained two states of $\mathrm{CD}$ isolate $\mathrm{ZvL2}-$ active, which is characterized by adhesive-invasive phenotype and resistance to macrophages, and inactive, which is similar to laboratory strain in terms of adhesion, invasion, and survival in macrophages. Active state is induced and supported by propionate but deteriorates by growth on glucose.

\section{The Proteome of CD Isolate ZvL2 Undergoes Rearrangement During Growth on Glucose or Propionate}

In order to reveal the physical basis of the observed phenotypic changes of $\mathrm{CD}$ isolate ZvL2 grown on different substrates, we performed proteome analysis using 2D differential electrophoresis. Figure $\mathbf{8}$ shows 2D differential proteome map of CD isolate ZvL2 grown on glucose and propionate for five passages. Red corresponds to cells grown on glucose, while 


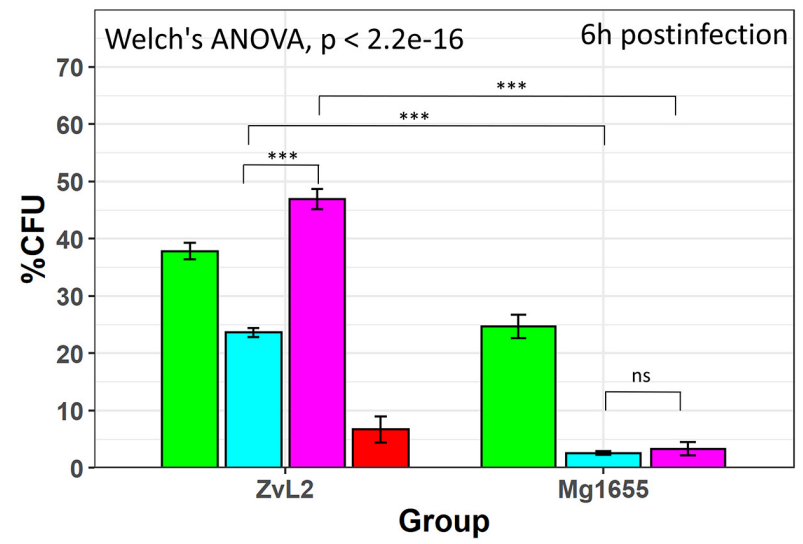

Condition $\square$ initial $\square$ Glu $\square$ PA $\square$ PA-Glu

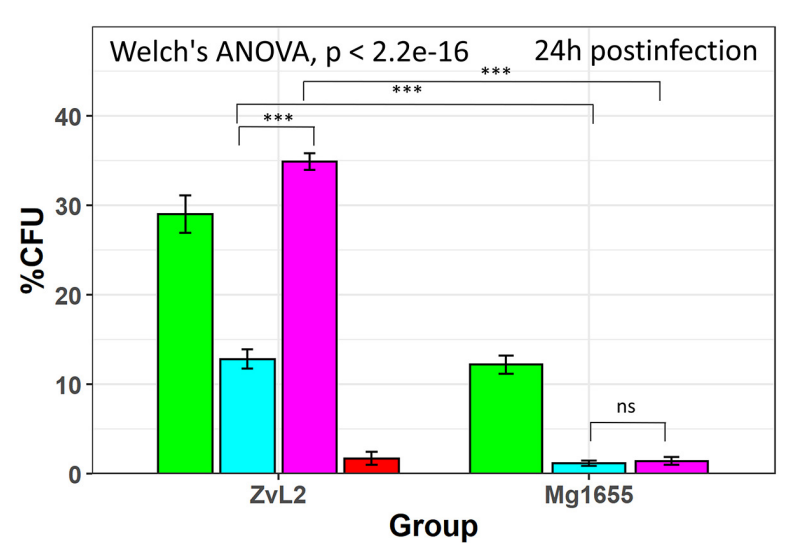

Condition $\square$ initial $\square$ Glu $\square$ PA $\square$ PA-Glu

FIGURE 7 | Survival and replication in macrophages (THP-1 cell line) of CD isolate ZvL2 and laboratory strain K12 Mg1655 grown on minimal M9 medium supplemented with glucose (Glu) or sodium propionate (PA) [ZVL2, K12 Mg1655-after one passage from colony on minimal M9 medium supplemented with glucose, ZvL2 Glu, Mg1655 Glu-after five passages from colony on minimal M9 medium supplemented with glucose, ZvL2 PA, Mg1655 PA-after five passages from colony in minimal M9 medium supplemented with sodium propionate after 6 (6 h) and $24 \mathrm{~h}$ (24 h) postinfection]. ZvL2 PA-Glu-re-passaging on M9 medium supplemented with glucose after sodium propionate. $1 \mathrm{hPI}$, the number of internalized bacteria during $1 \mathrm{~h}$ of postinfection. The number of internalized bacteria was, on average, three $E$. coli per macrophage. For all values, the mean $\pm \mathrm{SD}$ of six independent biological replicates are shown. ${ }^{\star} P \leq 0.05$, ${ }^{\star *} P \leq 0.01$, ${ }^{\star \star \star} P \leq 0.001$.

green corresponds to cells grown on propionate. The cutoff score for protein identification in the mascot engine was 44 $(p<0.05)$. A protein was identified as significantly changed

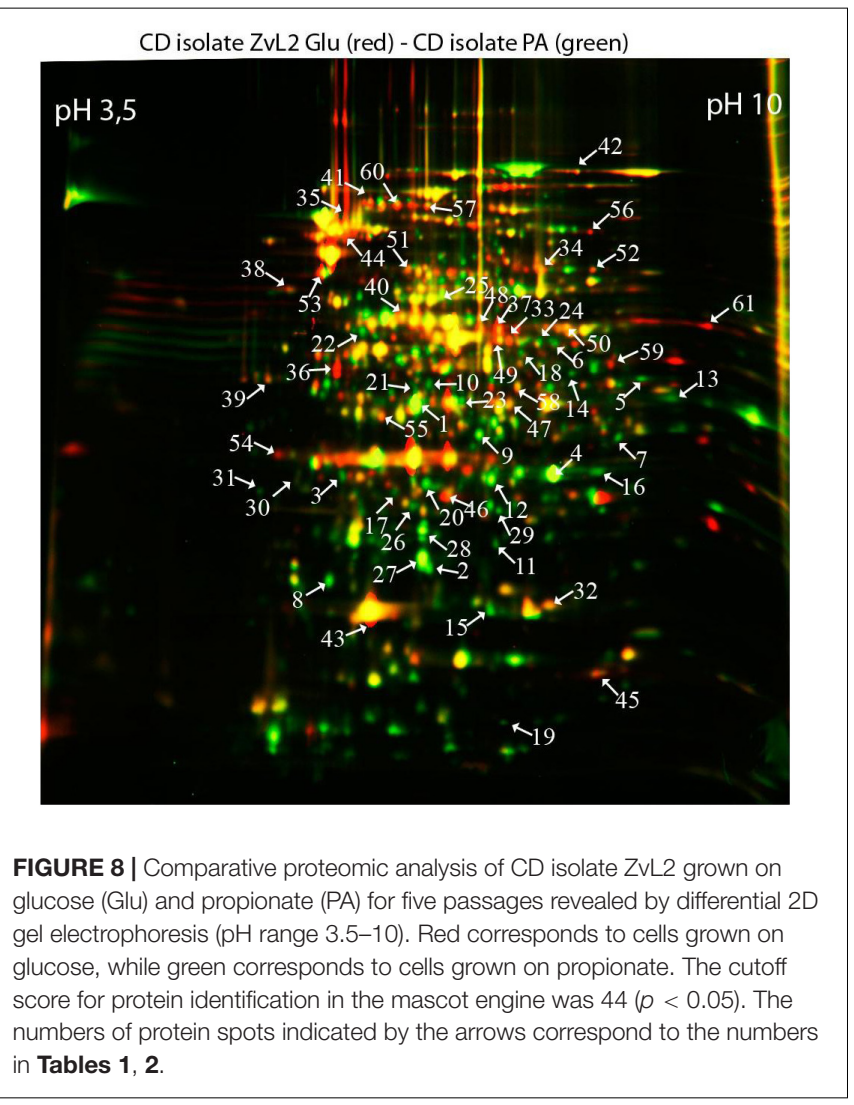

if the fold change was greater than 2 (up and down). Finally, we identified 60 differentially produced proteins (Tables 1, 2). First, we have to note the upregulation of porins $O m p A$ and $O m p W$ during growth on propionate. OmpA was previously identified as a pathogenicity factor that mediates colonization of macrophages by pathogenic E. coli (Sukumaran et al., 2003). Further significant amount of upregulated proteins is involved in RedOx homeostasis or protection from reactive oxygen species (Figures 8, 9). They include thioredoxin peroxidase $B t u E$, thiol peroxidase Tpx, thiol:disulfide interchange protein $D s b A$, cysteine desulfurase $I s c S$, Fe/S-clusters biogenesis protein $N f u A, \mathrm{NAD}(+)$ synthetase $\mathrm{NadE}$, menaquinone biosynthesis protein $M e n B$, and selenophosphate synthase SelD. In addition, there are two upregulated proteins that are involved in DNA protection: UspE and Dps. The latter also functions as iron storage and protects from oxidative stress caused by free $\mathrm{Fe}^{2+}$. Upregulation of UspE during growth on propionate is coupled with downregulation of its antagonist UspG. Another abundant group of upregulated proteins is linked to cell wall biogenesis: UDP- $N$-acetylglucosamine 1-carboxyvinyltransferase MurA, N-acetylglucosamine-6-phosphate deacetylase NagA, and endolytic peptidoglycan transglycosylase $R l p A$. Another interesting protein identified as significantly changed in our study is $S l p$. This protein has been shown to bind PIgR receptor on gut epithelium by enterohemorragic E. coli (Fedorchuk et al., 2019) and to play an important role in adherence. However, we identified decrease rather than increase of Slp during growth on propionate (Figure 9). Among the differentially expressed proteins identified by $2 \mathrm{D}$ electrophoresis, we found three transcription factors: $O m p R, P h o P$, and $M c b R$. These proteins are master regulators. $P h o P$ is a subunit of a two-component system with $P h o Q$. It is involved in the adaptation to low 
TABLE 1 | Proteins upregulated in ZvL2 isolate grown on M9 medium containing PA compared with cultivation on Glu.

\begin{tabular}{|c|c|c|c|c|}
\hline & Gene & Protein & Score & ZvL2 PA/ZvL2 Glu \\
\hline \multicolumn{5}{|c|}{ Membrane protein } \\
\hline 1 & KZO87574.1 & Porin OmpA & 87 & $4.09 \pm 0.53$ \\
\hline 2 & KZO85236.1 & Porin OmpW & 44 & $2.75 \pm 0.30$ \\
\hline \multicolumn{5}{|c|}{ Nucleotide metabolism } \\
\hline 3 & KZO86959.1 & Phosphoribosylaminoimidazole-succinocarboxamide synthase PurC & 158 & $2.24 \pm 0.39$ \\
\hline 4 & KZO81989.1 & Uridine phosphorylase Udp & 122 & $5.80 \pm 0.06$ \\
\hline 5 & KZO86279.1 & Guanosine 5'-monophosphate oxidoreductase GuaC & 71 & $2.71 \pm 0.30$ \\
\hline 6 & KZO86225.1 & Carbamoyl phosphate synthase small subunit CarA & 77 & $2.38 \pm 0.28$ \\
\hline \multicolumn{5}{|c|}{ Anaerobic growth } \\
\hline 7 & KZO86714.1 & Dihydroxynaphthoic acid synthetase MenB & 84 & $3.08 \pm 0.40$ \\
\hline \multicolumn{5}{|c|}{ Oxidative stress protection } \\
\hline 8 & KZO85295.1 & Peroxidase $T p x$ & 80 & $2.95 \pm 0.32$ \\
\hline 9 & KZO82481.1 & 2,5-diketo-D-gluconicacid reductase $D \mathrm{kgB}$ & 88 & $3.18 \pm 0.35$ \\
\hline \multicolumn{5}{|c|}{ Cell motility } \\
\hline 10 & KZO85303.1 & Universal stress protein UspE & 258 & $2.35 \pm 0.28$ \\
\hline \multicolumn{5}{|c|}{ Energy metabolism } \\
\hline 11 & KZO83151.1 & Dihydroxyacetone kinase DhaL & 136 & $2.33 \pm 0.28$ \\
\hline 12 & KZO85449.1 & Triosephosphate isomerase TpiA & 177 & $4.18 \pm 0.54$ \\
\hline 13 & KZO87259.1 & Glyceraldehyde-3-phosphate dehydrogenase GapA & 168 & $2.37 \pm 0.25$ \\
\hline 14 & KZO81926.1 & N-acetylglucosamine-6-phosphate deacetylase NagA & 67 & $2.01 \pm 0.22$ \\
\hline \multicolumn{5}{|c|}{ Chromosome structure } \\
\hline 15 & KZO86055.1 & Nucleoid-associated protein Dps & 147 & $3.19 \pm 0.35$ \\
\hline \multicolumn{5}{|c|}{ Transcription factors } \\
\hline 16 & KZO86488.1 & Transcriptional regulator $O m p R$ & 62 & $2.98 \pm 0.29$ \\
\hline 17 & KZO84903.1 & Transcriptional regulator $P h o P$ & 131 & $2.05 \pm 0.24$ \\
\hline \multicolumn{5}{|c|}{ Use of alternative carbon sources } \\
\hline 18 & KZO86735.1 & Acetate kinase AckA & 161 & $2.56 \pm 0.33$ \\
\hline \multicolumn{5}{|c|}{ Amino acid biosynthesis and catabolism } \\
\hline 19 & KZO84886.1 & Purine nucleoside phosphoramidase HinT & 47 & $2.00 \pm 0.11$ \\
\hline 20 & KZO84529.1 & 3-dehydroquinate dehydratase $A r o D$ & 100 & $3.67 \pm 0.46$ \\
\hline 21 & KZO87274.1 & Selenophosphate synthetase SelD & 70 & $2.07 \pm 0.25$ \\
\hline \multicolumn{5}{|c|}{ Cell wall synthesis } \\
\hline 22 & KZO87791.1 & UDP-N-acetylglucosamine 1-carboxyvinyl transferase MurA & 46 & $2.19 \pm 0.28$ \\
\hline \multicolumn{5}{|c|}{ Other functions } \\
\hline 23 & KZO87292.1 & NAD synthetase NadE & 187 & $3.87 \pm 0.50$ \\
\hline 24 & KZO87002.1 & Cysteine desulfurase IscS & 61 & $1.98 \pm 0.15$ \\
\hline 25 & KZO81874.1 & Aminoacyl-histidine dipeptidase $P e p D$ & 184 & $2.54 \pm 0.33$ \\
\hline \multicolumn{5}{|c|}{ Proteins with unknown function } \\
\hline 26 & KZO87561.1 & Hypothetical protein TH54_02655 & 92 & $1.99 \pm 0.13$ \\
\hline \multicolumn{5}{|c|}{ Chaperones } \\
\hline 27 & KZO82051.1 & Heat shock protein $I b p A$ & 109 & $4.01 \pm 0.52$ \\
\hline \multicolumn{5}{|c|}{ Redox cell homeostasis } \\
\hline 28 & KZO85494.1 & Protein disulfide isomerase $D s b D$ & 73 & $3.15 \pm 0.40$ \\
\hline 29 & KZO82128.1 & Zinc/cadmium-binding protein ZinT & 136 & $1.98 \pm 0.11$ \\
\hline 30 & KZO83979.1 & 2,3-dihydroxybenzoate-2,3-dehydrogenase EntA & 66 & $1.97 \pm 0.11$ \\
\hline 31 & KZO86481.1 & $\mathrm{Fe} / \mathrm{S}$ biogenesis protein NfuA & 86 & $1.99 \pm 0.12$ \\
\hline
\end{tabular}

$\mathrm{Mg}^{2+}$ concentrations and oxidative stress (Kato et al., 1999). Recently, it has been shown that the PhoP/PhoQ signal pathway is involved in extraintestinal pathogenic E. coli survival in macrophages (Zhuge et al., 2018). OmpR is a global regulator that controls oxidative and osmotic stress and is involved in the regulation of virulence and metabolism (Chakraborty and Kenney, 2018). McbR increases biofilm formation by repressing overproduction of the exopolysaccharide identified as colanic acid (Zhang et al., 2008). Using RegulonDB database ${ }^{1}$, we searched the targets of the identified regulators within the proteins differentially expressed on $2 \mathrm{D} \mathrm{EF}$. We identified only two direct targets: $\arg D$ (acetylornithine/succinyl-diaminopimelate

${ }^{1}$ http://regulondb.ccg.unam.mx/ 
TABLE 2 | Proteins downregulated in ZVL2 isolate grown on M9 medium containing PA compared with cultivation on Glu.

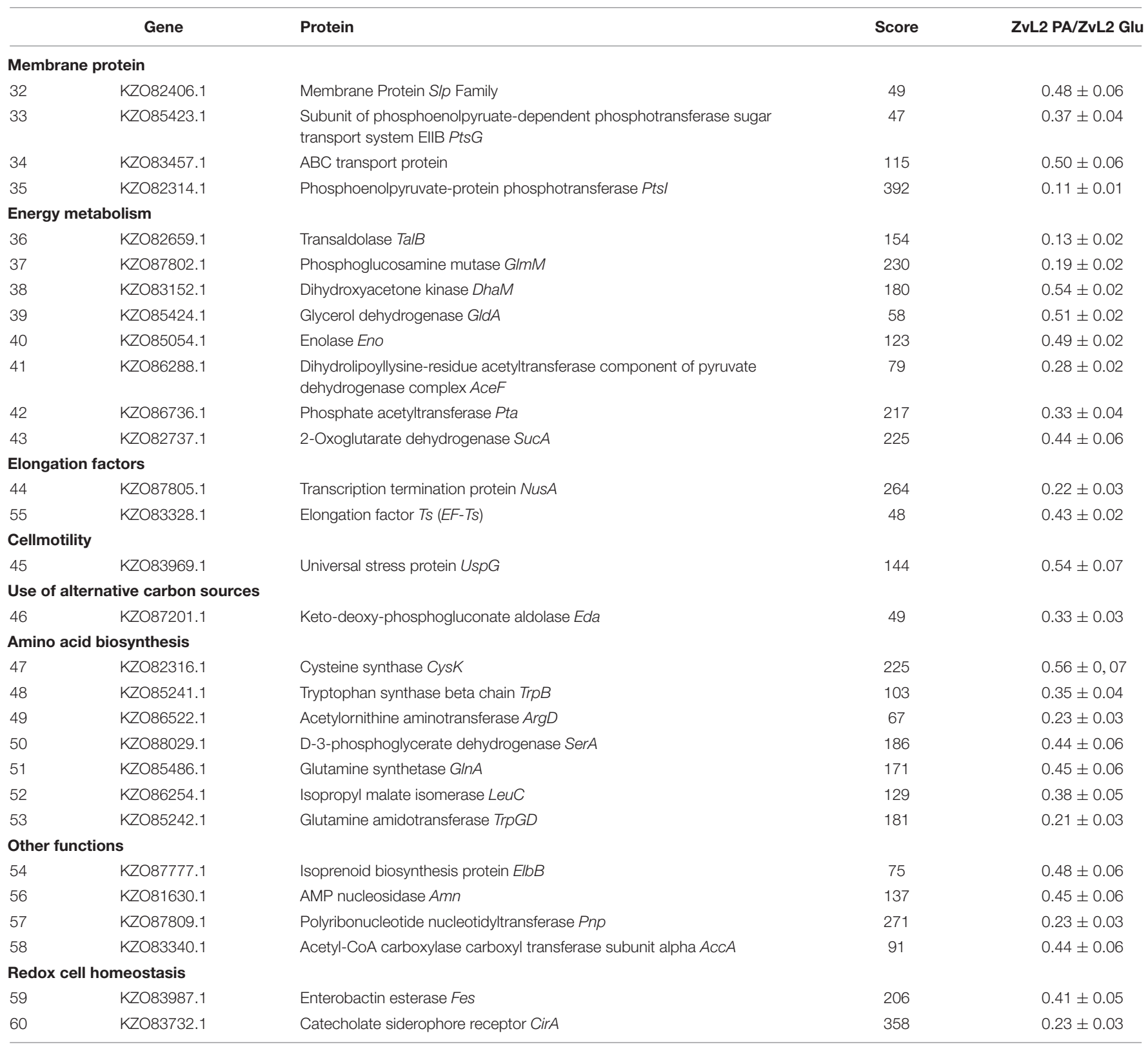

aminotransferase) and nagA ( $\mathrm{N}$-acetylglucosamine-6-phosphate deacetylase). The observed changes may be the result of indirect regulation. For example, PhoP regulates eight transcription factors and two ncRNAs (according to RegulonDB).

\section{DISCUSSION}

We demonstrated that $\mathrm{CD}$ isolate ZvL2 features adhesiveinvasive phenotype and can efficiently survive in macrophages in comparison to the laboratory strain K-12 MG1655. CD isolate ZvL2 is capable of utilization of propionate, which serves as an inductor of adhesive-invasive and macrophage resistance properties. Similar observations were made for another $\mathrm{CD}$ isolate LF82 (Ormsby et al., 2018, 2019). The adhesive-invasive phenotype was found to be dependent on the carbon source. Prolonged growth on glucose reduces pathogenicity to the levels of laboratory strain, while prolonged growth on propionate promotes it. This finding is striking since propionate has been considered as a health-promoting metabolite for the gut (Hosseini et al., 2011). It should be noted that propionate does not have a similar effect on the laboratory strain K12MG1655, despite the fact that it can also adapt and grow on this carbon source. The effect of propionate is reversible, re-passaging of CD isolate on M9 medium supplemented with glucose leads to the loss of its virulent properties. Comparative proteome analysis identified a set of proteins that are potentially important for the observed phenotype switching. They represent porins; 


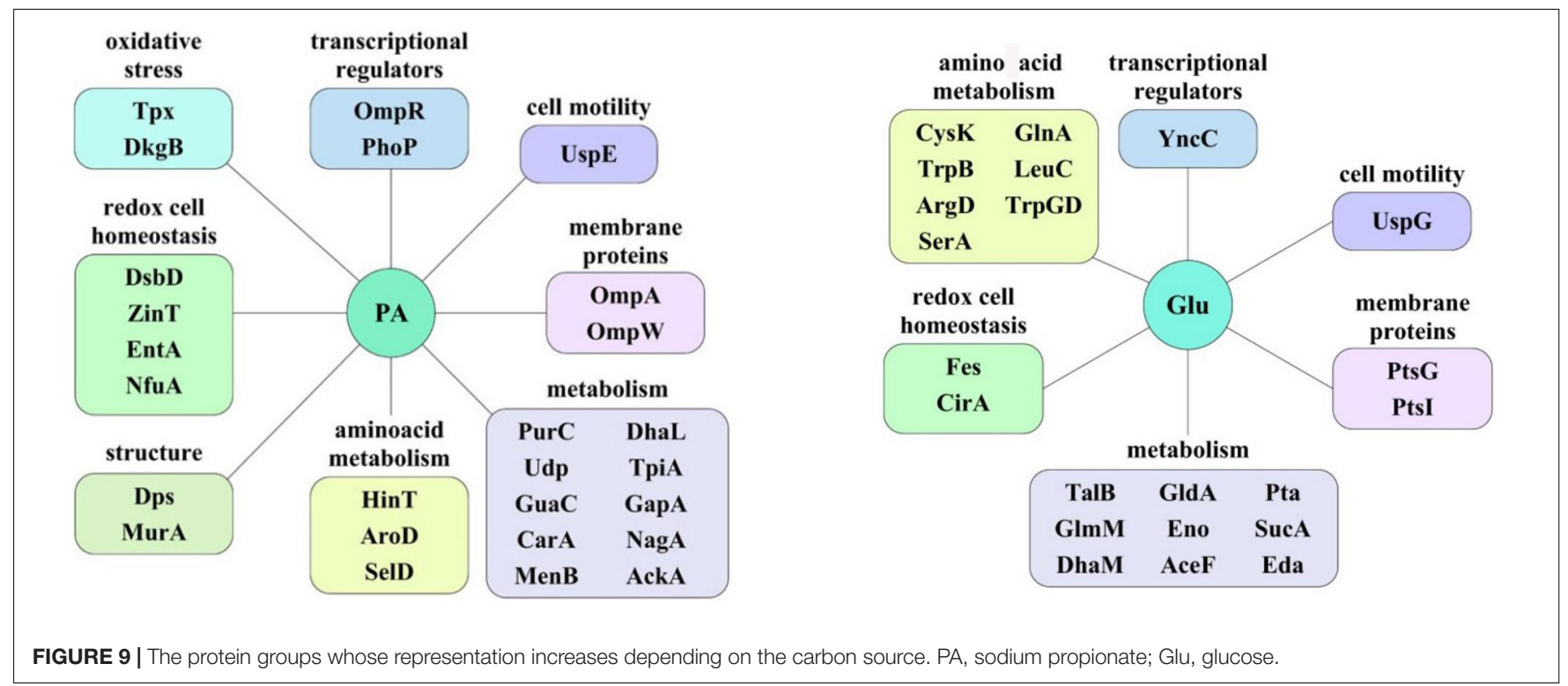

transcription factors $O m p R, P h o P$, and $M c b R$; proteins involved in protection from reactive oxygen species; and proteins involved in cell wall biogenesis (Figure 9).

Porin OmpA represents a multi-functional protein that is important for pathogenesis. OmpA can block activation of complement via binding to C4-binding protein (Prasadarao et al., 2002). OmpA mediates E. coli phagocytosis, survival, and growth in macrophages, which in turn may lead to macrophage lysis. The mechanism of OmpA-dependent E. coli engulfment differs from the OmpA-knockout cells. OmpA-expressing E. coli induce actin condensation in the site of entry and the engulfment does not depend on macrophage integrins (Sukumaran et al., 2003). OmpW has been demonstrated to suppress E. coli phagocytosis by macrophages (Wu et al., 2013). Thus, we propose that OmpA and OmpW may work together: $O m p W$ blocks normal phagocytosis, while OmpA induces abnormal phagocytosis, which instead of bacteria lysis in the phagosome results in their propagation. In addition, it was shown that in AIEC strain LF82, deletion of the ompA gene significantly decreased the ability of the bacteria to invade Intestine- 407 epithelial cells compared to a wild-type strain and results in a loss of fusion of outer membrane vesicles with the host cell membrane (Rolhion et al., 2010).

Multiple defensive and functionally related proteins are induced after growth on propionate (Figure 9). Peroxidases and proteins involved in $\mathrm{Fe}-\mathrm{S}$ cluster biosynthesis have a direct role in resistance to oxidative stress. Stress protein UspE has multiple roles in adaptation to environmental perturbations (Tkaczuk et al., 2013). It may protect cells from heavy metals (Xu et al., 2016) and regulate the formation of flagella (Hosseini et al., 2011). UspE changes expression cooperatively with its antagonist UspG (Nachin et al., 2005; Siegele, 2005). Increase of UspE occurs simultaneously with decrease of $U s p G$ and vice versa. $D p s$ protein upregulated during growth on propionate serves as DNA protector and in addition stores iron (Kim et al., 2004; Karas et al., 2015). In addition, growth on propionate induces DhbA, enzyme involved in enterobactin siderophore synthesis and decreases enterobactin esterase, involved in its degradation. The latter may be important since depletion of iron is an important defensive strategy of hosts against pathogens (Saha et al., 2019). Upregulated during growth on propionate inner membrane protein $D s b D$ is a part of the protein complex responsible for stabilization of intramolecular disulfide bridges between cysteine residues of the exported proteins. It is maintained in the reduced form by the periplasmic oxidoreductase $D s b A$. It is known that $D s b A$ was required for AIEC strain LF82 to adhere to intestinal epithelial cells and to survive within macrophages (Bringer et al., 2007). The LF82-dsbA mutant did not express flagella and, probably as a consequence of this, did not express type 1 pili. There is evidence that the $d s b A$ gene is needed for LF82 bacteria to grow and survive in an acidic and nutrient-poor medium that partly mimics the harsh environment of the phagocytic vacuole. Under such stress conditions, $d s b A$ transcription is highly upregulated.

Thus, propionate induces complex reprogramming of pathogenic E. coli strain to the process of infection. We found that propionate induced an increased level of proteins, which are known pathogenicity factors, among them, proteins $O m p A$, $O m p W, P h o P, O m p R$, and $U s p E$. The data obtained in this study suggest that $E$. coli gets ready to suppress normal phagocytosis and induce macrophage infection and raises defense against oxidative burst beforehand.

\section{CONCLUSION}

This study revealed that the activity of $E$. coli with an adhesiveinvasive phenotype depends on the carbon source in the culture medium. In particular, the prolonged growth of E. coli isolate obtained by our group from a patient with CD on a M9 medium supplemented with sodium propionate significantly stimulates its adhesive-invasive properties and survival in macrophages, while 
prolonged passaging on a glucose containing medium, on the contrary, significantly reduces these properties. The cultivation of the CD isolate on different carbon sources made it possible to obtain the same isolate in two different states of activity. A comparative proteomic analysis of these states showed that the propionate induces expression of important pathogenic factors, among them porins, transcription factors, proteins involved in the protection against oxidative stress, and cell wall biogenesis.

\section{DATA AVAILABILITY STATEMENT}

The datasets generated and analysed during the current study are partially available in the Supplementary Material. The rest of the data is available from the corresponding author on reasonable request.

\section{AUTHOR CONTRIBUTIONS}

All authors have made direct experimental and/or intellectual contribution to the work, and have read and approved the final

\section{REFERENCES}

Boudeau, J., Glasser, A. L., Neut, C., Desreumaux, P., Cortot, A., Rich, C., et al. (2000). Invasive ability of Escherichia coli strains isolated from ileal mucosa in Crohn's disease. Gastroenterology 118:A1847.

Bringer, M. A., Glasser, A. L., Tung, C. H., Méresse, S., and Darfeuille-Michaud, A. (2006). The Crohn's disease-associated Adherent invasive Escherichia coli strain LF82 replicates in mature phagolysosomes within J774 macrophages. Cell Microbiol. 8, 471-484. doi: 10.1111/j.1462-5822.2005.00639.x

Bringer, M. A., Rolhion, N., Glasser, A. L., and Darfeuille-Michaud, A. (2007). The oxidoreductase DsbA plays a key role in the ability of the Crohn's disease-associated adherent-invasive Escherichia coli strain LF82 to resist macrophage killing. J. Bacteriol. 189, 4860-4871. doi: 10.1128/JB. 00233-07

Chakraborty, S., and Kenney, L. J. (2018). A New Role of OmpR in Acid and Osmotic Stress in Salmonella and E. coli. Front. Microbiol. 22:2656. doi: 10.3389/ fmicb.2018.02656

Conte, M. P., Longhi, C., Marazzato, M., Conte, A. L., Aleandri, M., Lepanto, M. S., et al. (2014). Adherent-invasive Escherichia coli (AIEC) in pediatric Crohn's disease patients: phenotypic and genetic pathogenic features. BMC Res. Notes 7:748. doi: 10.1186/1756-0500-7-748

Crow, J. F., and Kimura, M. (1970). An Introduction to Population Genetics Theory. Caldwell, NJ: Harper and Row, Publishers, Inc.

Cummings, J. H., Pomare, E. W., Branch, W. J., Naylor, C. P., and Macfarlane, G. T. (1987). Short chain fatty acids in human large intestine, portal, hepatic and venous blood. Gut. 28, 1221-1227. doi: 10.1136/gut.28. 10.1221

Fedorchuk, C., Kudva, I. T., and Kariyawasam, S. (2019). The Escherichia coli O157:H7 carbon starvation-inducible lipoprotein Slp contributes to initial adherence in vitro via the human polymeric immunoglobulin receptor. PLoS One 14:e0216791. doi: 10.1371/journal.pone.0216791

Ferreyra, J. A., Ng, K. M., and Sonnenburg, J. L. (2014). The enteric two-step: nutritional strategies of bacterial pathogens within the gut. Cell Microbiol. 16, 993-1003. doi: 10.1111/cmi.12300

Fisunov, G. Y., Alexeev, D. G., Bazaleev, N. A., Ladygina, V. G., Galyamina, M. A., Kondratov, I. G., et al. (2011). Core proteome of the minimal cell: comparative proteomics of three mollicute species. PLoS One 6:e21964. doi: 10.1371/journal. pone.0021964

Garanina, I. A., Fisunov, G. Y., and Govorun, V. M. (2018). The tool for visualization and analysis of prokaryotic genomes. Front. Microbiol. 9:2827. doi: $10.3389 /$ fmicb. 2018.02827 version. OP and VL designed the study, analysis of adhesive and invasive properties and survival in macrophages of $E$. coli, and 2D electrophoresis. AE contributed to cultivation of the cell cultures. DE and GF contributed to quantitative real-time PCR and comparison of genes and pathways related to propionate degradation. DM contributed to mass spectrometric analysis. AZ contributed to text editing and data processing.

\section{FUNDING}

This work was supported by the Russian Science Foundation (Project No. 16-15-00258).

\section{SUPPLEMENTARY MATERIAL}

The Supplementary Material for this article can be found online at: https://www.frontiersin.org/articles/10.3389/fmicb. 2020.01460/full\#supplementary-material

Gevers, D., Kugathasan, S., Denson, L. A., Vázquez-Baeza, Y., Van Treuren, W., Ren, B., et al. (2014). The treatment-naive microbiome in new-onset Crohn's disease. Cell Host Microbe 15, 382-392. doi: 10.1016/j.chom.2014. 02.005

Gorbachev, A. Y., Fisunov, G. Y., Izraelson, M., Evsyutina, D. V., Mazin, P. V., Alexeev, D. G., et al. (2013). DNA repair in Mycoplasma gallisepticum. BMC Genomics 14:726. doi: 10.1186/1471-2164-14-726

Hornef, M. (2015). Pathogens, commensal symbionts, and pathobionts: discovery and functional effects on the host. ILAR J. 56, 159-162. doi: 10.1093/ilar/ ilv007

Hosseini, E., Grootaert, C., Verstraete, W., and Van de Wiele, T. (2011). Propionate as a health-promoting microbial metabolite in the human gut. Nutr Rev. 69, 245-258. doi: 10.1111/j.1753-4887.2011.00388.x

Hung, C. C., Garner, C. D., Slauch, J. M., Dwyer, Z. W., Lawhon, S. D., Frye, J. G., et al. (2013). The intestinal fatty acid propionate inhibits Salmonella invasion through the post-translational control of HilD. Mol. Microbiol. 87, 1045-1060. doi: $10.1111 / \mathrm{mmi} .12149$

Karas, V. O., Westerlaken, I., and Meyer, A. S. (2015). The DNA-binding protein from starved cells (Dps) utilizes dual functions to defend cells against multiple stresses. J. Bacteriol. 197, 3206-3215. doi: 10.1128/JB. 00475-15

Kato, A., Tanabe, H., and Utsumi, R. (1999). Molecular characterization of the PhoP-PhoQ two-component system in Escherichia coli K-12: identification of extracellular Mg2+-responsive promoters. J. Bacteriol. 181, 5516-5520. doi: 10.1128/jb.181.17.5516-5520.1999

Kim, J., Yoshimura, S. H., Hizume, K., Ohniwa, R. L., Ishihama, A., and Takeyasu, K. (2004). Fundamental structural units of the Escherichia coli nucleoid revealed by atomic force microscopy. Nucleic Acids Res. 32, 1982-1992. doi: 10.1093/nar/ gkh512

Lapaquette, P., Bringer, M. A., and Darfeuille-Michaud, A. P. (2012). Defects in autophagy favour adherent-invasive Escherichia coli persistence within macrophages leading to increased pro-inflammatory response. Cell. Microbiol. 14, 791-807. doi: 10.1111/j.1462-5822.2012.01768.x

Liu, F., Gu, J., Wang, X., Zhang, X. E., and Deng, J. (2014). Acs is essential for propionate utilization in Escherichia coli. Biochem. Biophys. Res .Commun. 449, 272-277. doi: 10.1016/j.bbrc.2014.05.015

Liu, Y., Leal, N. A., Sampson, E. M., Johnson, C. L., Havemann, G. D., Bobik, T., et al. (2007). PduL is an evolutionarily distinct phosphotransacylase involved in B12-dependent 1,2-propanediol degradation by Salmonella entericaserovartyphimurium LT2. J. Bacteriol. 189, 1589-1596. doi: 10.1128/JB. 01151-06 
Migliore, F., Macchi, R., Landini, P., and Paroni, M. (2018). Phagocytosis and Epithelial Cell Invasion by Crohn's Disease-Associated AdherentInvasive Escherichia coli Are Inhibited by the Anti-inflammatory Drug 6Mercaptopurine. Front. Microbiol. 9:964. doi: 10.3389/fmicb.2018.00964

Miquel, S., Peyretaillade, E., Claret, L., de Vallée, A., Dossat, C., Vacherie, B., et al. (2010). Complete genome sequence of Crohn's disease-associated adherentinvasive E. coli strain LF82. PLoS One 5:e12714. doi: 10.1371/journal.pone. 0012714

Nachin, L., Nannmark, U., and Nyström, T. (2005). Differential roles of the universal stress proteins of Escherichia coli in oxidative stress resistance, adhesion, and motility. J. Bacteriol. 187, 6265-6272. doi: 10.1128/JB.187.18. 6265-6272.2005

Nash, J. H., Villegas, A., Kropinski, A. M., Aguilar-Valenzuela, R., Konczy, P., Mascarenhas, M., et al. (2010). Genome sequence of Adherentinvasive Escherichia coli and comparative genomic analysis with other E. coli pathotypes. BMC Genomics 11:667. doi: 10.1186/1471-216411-667

Ng, S. C., Shi, H. Y., Hamidi, N., Underwood, F. E., Tang, W., Benchimol, E. I, et al. (2018). Worldwide incidence and prevalence of inflammatory bowel disease in the 21st century: a systematic review of population-based studies. Lancet 390, 2769-2778. doi: 10.1016/S0140-6736(17)32448-0

Olivares-Morales, M. J., De La Fuente, M. K., Dubois-Camacho, K., Parada, D., Diaz-Jiménez, D., Torres-Riquelme, A., et al. (2018). Glucocorticoids impair phagocytosis and inflammatory response against crohn's disease-associated adherent-invasive Escherichia coli. Front Immunol. 16:1026. doi: 10.3389/ fimmu.2018.01026

Ormsby, M. J., Johnson, S. A., Meikle, L. M., Goldstone, R. J., McIntosh, A., Wessel, H. M., et al. (2018). Propionic acid enhances the virulence of Crohn's diseaseassociated adherent-invasive Escherichia coli. bioRxiv [Preprint] doi: 10.1101/ 387647

Ormsby, M. J., Logan, M., Johnson, S. A., McIntosh, A., Fallata, G., Papadopoulou, R., et al. (2019). Inflammation associated ethanolamine facilitates infection by Crohn's disease-linked adherent-invasive Escherichia coli. EBiomedicine 43, 325-332. doi: 10.1016/j.ebiom.2019.03.071

Palacios, S., Stara, I. V. J., and Escalante-Semerena, J. C. (2003). Propionyl coenzyme $\mathrm{A}$ is a common intermediate in the 1,2-propanediol and propionate catabolic pathways needed for expression of the prpBCDE operon during growth of Salmonella enterica on 1,2-propanediol. J. Bacteriol. 185, 2802-2810. doi: 10.1128/jb.185.9.2802-2810.2003

Prasadarao, N. V., Blom, A. M., Villoutreix, B. O., and Linsangan, L. C. (2002). A novel interaction of outer membrane protein A with $\mathrm{C} 4 \mathrm{~b}$ binding protein mediates serum resistance of Escherichia coli K1. J. Immunol. 169, 6352-6360. doi: 10.4049/jimmunol.169.11.6352

Rakitina, D. V., Manolov, A. I., Kanygina, A. V., Garushyants, S. K., Baikova, J. P., Alexeev, D. G., et al. (2017). Genome analysis of E. coli isolated from Crohn's disease patients. BMC Genomics 18:544. doi: 10.1186/s12864-017-3917-x

Rhodes, J. M. (2007). The role of Escherichia coli in inflammatory bowel disease. Gut 56, 610-612. doi: 10.1136/gut.2006. 111872

Rocco, C. J., and Escalante-Semerena, J. C. (2010). In Salmonella enterica, 2 methylcitrate blocks gluconeogenesis. J. Bacteriol. 192, 771-778. doi: 10.1128/ JB.01301-09

Rockwood, L. L. (2015). Introduction to Population Ecology, 2nd Edn. West Sussex: Wiley.

Rolhion, N., Barnich, N., Bringer, M. A., Glasser, A. L., Ranc, J., Hébuterne, X., et al. (2010). Abnormally expressed ER stress response chaperone Gp96 in CD favours adherent-invasive Escherichia coli invasion. Gut 59, 1355-1362. doi: 10.1136/gut.2010.207456

Saha, P., Xiao, X., Yeoh, B. S., Chen, Q., Katkere, B., Kirimanjeswara, G. S., et al. (2019). The bacterial siderophore enterobactin confers survival advantage to Salmonella in macrophages. Gut Microbes. 10, 412-423. doi: 10.1080/19490976. 2018.1546519

Schippa, S., Iebba, V., Totino, V., Santangelo, F., Lepanto, M., Alessandri, C., et al. (2012). A potential role of Escherichia coli pathobionts in the pathogenesis of pediatric inflammatory bowel disease. Can. J. Microbiol. 58, 426-432. doi: 10.1139/w2012-007
Shevchenko, A., Wilm, M., Vorm, O., and Mann, M. (1996). Mass spectrometric sequencing of proteins silver-stained polyacrylamide gels. Anal. Chem. 68, 850-858. doi: 10.1021/ac950914h

Siegele, D. A. (2005). Universal stress proteins in Escherichia coli. J. Bacteriol. 187, 6253-6254. doi: 10.1128/JB.187.18.6253-6254.2005

Simonte, F. M., Dötsch, A., Galego, L., Arraiano, C., and Gescher, J. (2017). Investigation on the anaerobic propionate degradation by Escherichia coli K12. Mol. Microbiol. 103, 55-66. doi: 10.1111/mmi.13541

Sprouffske, K., and Wagner, A. (2016). Growthcurver: an R package for obtaining interpretable metrics from microbial growth curves. BMC Bioinformatics 17:172. doi: 10.1186/s12859-016-1016-7

Staib, L., and Fuchs, T. M. (2014). From food to cell: nutrient exploitation strategies of enteropathogens. Microbiology 160, 1020-1039. doi: 10.1099/mic.0.078105-0

Starr, T., Bauler, T. J., Malik-Kale, P., and Steele-Mortimer, O. (2018). The phorbol 12-myristate-13-acetate differentiation protocol is critical to the interaction of THP-1 macrophages with Salmonella typhimurium. PLoS One 13:e0193601. doi: 10.1371/journal.pone.0193601

Stecher, B. (2015). The roles of inflammation, nutrient availability and the commensal microbiota in enteric pathogen infection. Microbiol. Spectr. 3, 1-17. doi: 10.1128/microbiolspec.MBP-0008-2014

Stewart C. N. and Via, L. E. (1993). A rapid CTAB DNA isolation technique useful for RAPD fingerprinting and other PCR applications. Biotechniques 15, $748-750$.

Strober, W. (2011). Adherent-invasive E. coli in Crohn disease: bacterial "agent provocateur". J. Clin. Invest. 121, 841-844. doi: 10.1172/jci46333

Sukumaran, S. K., Shimada, H., and Prasadarao, N. V. (2003). Entry and intracellular replication of Escherichia coli $\mathrm{K} 1$ in macrophages require expression of outer membrane protein A. Infect. Immun. 71, 5951-5961. doi: 10.1128/iai.71.10.5951-5961.2003

Suvorova, I. A., Ravcheev, D. A., and Gelfand, M. S. (2012). Regulation and evolution of malonate and propionate catabolism in proteobacteria. J. Bacteriol. 194, 3234-3240. doi: 10.1128/JB.00163-12

Tkaczuk, K. L., Shumilin, I. A., Chruszcz, M., Evdokimova, E., Savchenko, A., and Minor, W. (2013). Structural and functional insight into the universal stress protein family. Evol. Appl. 6, 434-449. doi: 10.1111/eva.12057

Torres, J., Mehandru, S., Colombel, J. F., and Peyrin-Biroulet, L. (2017). Crohn's disease. Lancet 389, 1741-1755. doi: 10.1016/S0140-6736(16)31711-1

Wu, X. B., Tian, L. H., Zou, H. J., Wang, C. Y., Yu, Z. Q., Tang, C. H., et al. (2013). Outer membrane protein OmpW of Escherichia coli is required for resistance to phagocytosis. Res. Microbiol. 164, 848-855. doi: 10.1016/j.resmic.2013.06.008

Xu, Y., Guo, J., Jin, X., Kim, J. S., Ji, Y., Fan, S., et al. (2016). Crystal structure and functional implications of the tandem-type universal stress protein UspE from Escherichia coli. BMC Struct. Biol. 16:3. doi: 10.1186/s12900-016-0053-59

Zgoda, V., Tikhonova, O., Viglinskaya, A., Serebriakova, M., Lisitsa, A., and Archakov, A. (2006). Proteomic profiles of induced hepatotoxicity at the subcellular level. Proteomics 6, 4662-4670. doi: 10.1002/pmic.200600342

Zhang, X. S., García-Contreras, R., and Wood, T. K. (2008). Escherichia coli transcription factor YncC (McbR) regulates colanic acid and biofilm formation by repressing expression of periplasmic protein YbiM (McbA). ISME J. 2, 615-631. doi: 10.1038/ismej.2008.24

Zhuge, X., Sun, Y., Xue, F., Tang, F., Ren, J., Li, D., et al. (2018). Novel PhoP/PhoQ regulation pathway modulates the survival of ExtraintestinalPathogenicEscherichia coli in macrophages. Front. Immunol. 17:788. doi: 10.3389/fimmu.2018.00788

Conflict of Interest: The authors declare that the research was conducted in the absence of any commercial or financial relationships that could be construed as a potential conflict of interest.

Copyright (c) 2020 Pobeguts, Ladygina, Evsyutina, Eremeev, Zubov, Matyushkina, Scherbakov, Rakitina and Fisunov. This is an open-access article distributed under the terms of the Creative Commons Attribution License (CC BY). The use, distribution or reproduction in other forums is permitted, provided the original author(s) and the copyright owner(s) are credited and that the original publication in this journal is cited, in accordance with accepted academic practice. No use, distribution or reproduction is permitted which does not comply with these terms. 